(2) Open Access Full Text Article

CLINICALTRIAL REPORT

\title{
Levobupivacaine Consumption in Automated Intermittent Bolus in Ultrasound Guided Subparaneural Sciatic Nerve Catheters: A Prospective Double-Blind Randomized Trial
}

This article was published in the following Dove Press journal:

Local and Regional Anesthesia

\author{
Margaretha B Breebaart (ID ${ }^{1,2}$ \\ Jordi Branders ${ }^{2}$ \\ Luc Sermeus ${ }^{3}$ \\ Sultan Termurziev ${ }^{2}$ \\ Helene Camerlynck ${ }^{2}$ \\ Lennert Van Putte $\mathbb{D}^{1}$ \\ Marnik Van Putte Minelli' \\ Stefan De Hert (iD ${ }^{4}$ \\ 'Faculty of Medicine and Health Sciences, \\ Antwerp University, Wilrijk, Belgium; \\ ${ }^{2}$ Department of Anesthesia, Antwerp \\ University Hospital, Edegem, Belgium; \\ ${ }^{3}$ Department of Anesthesiology, St. Luc \\ University Hospital, Brussels, Belgium; \\ ${ }^{4}$ Department of Anesthesia and \\ Perioperative Medicine, Ghent University \\ Hospital, Ghent, Belgium
}

Correspondence: Margaretha B Breebaart Department of Anesthesia, Antwerp University Hospital, Wilrijkstraat 10,

Edegem, 2650, Belgium

Tel +32 4869|1691

Email Margaretha.breebaart@uza.be

\begin{abstract}
Purpose: Continuous sciatic nerve blocks have proven benefits for postoperative analgesia after foot surgery. However, the optimal mode of administration remains a point of debate. Ultrasound guided subparaneural injection accelerates onset time and increases duration after a single shot sciatic nerve block. This double blind prospective randomized trial compares the 48-hour local anesthetic (LA) dose consumption of an automated intermittent bolus technique to a continuous infusion regimen in a subparaneural sciatic nerve catheter after hallux valgus surgery.
\end{abstract}

Patients and Methods: Patients scheduled for hallux valgus surgery were randomized to receive either a continuous infusion of levobupivacaine $0.125 \%$ at $5 \mathrm{~mL} / \mathrm{h}$ (group A) or an intermittent automated bolus of $9.8 \mathrm{~mL}$ every 2 hours with a background of $0.1 \mathrm{~mL} / \mathrm{h}$ (group B), both with a PCA bolus of $6 \mathrm{~mL}$ and lockout of 30 minutes. The 48 hour LA consumption, PCA boluses, Numeric Rating Scale (NRS), satisfaction and return of normal sensation were recorded.

Results: Sixteen patients were excluded because of protocol violation or technical problems and 42 patients remained for analysis. The 48 hour ropivacaine consumption was higher in group A $(293 \pm 60 \mathrm{~mL})$ than group B $(257 \pm 33 \mathrm{~mL})$. The median and highest NRS scores and patient satisfaction were not statistically different between groups. Normal sensation returned after $75 \pm 22$ hours (group A) and $70 \pm 17$ hours (group B).

Conclusion: Programmed bolus administration in subparaneural sciatic nerve catheters reduces LA consumption 48 hours after surgery with equal analgesia and patient satisfaction. Return of sensation is variable and can last more than 75 hours.

Keywords: locoregional anesthesia, sciatic nerve block, postoperative pain, local anesthetics, levobupivacaine, orthopedic surgery

\section{Introduction}

Continuous sciatic nerve blocks have proven benefits for postoperative analgesia after foot and ankle surgery. ${ }^{1-4}$ However, the optimal mode of administering local anesthetic (LA) remains a point of debate. Several studies have been performed looking at the best volume, dose, concentration, and administration technique of local anesthetics. ${ }^{5,6}$ Theoretically, the optimal LA dose for sciatic nerve catheters provides good analgesia with minimal motor block, no disturbing numbness, low risk of local anesthetic systemic toxicity and a low threshold for detecting compartment syndrome. 
With the development of technology, it has become possible to administer more sophisticated LA regimens such as programmed intermittent bolus administration (PIB). The epidural use of PIB has been shown to reduce the need for LA during labor. ${ }^{7}$ However, its potential benefit in reducing LA need for satisfactory analgesia in orthopedic interventions is less established.

In this prospective double-blind randomized trial, we aimed to investigate whether the application of the PIB technique allowed a reduced administration of LA during a subparaneural sciatic nerve block for orthopedic foot surgery. We hypothesized that with PIB, less LA would be needed during the first 48 hours after surgery to obtain adequate postoperative analgesia $(\mathrm{NRS}<4)$ compared to continuous infusion combined with patient-controlled analgesia (PCA). The primary outcome variable was LA consumption during the first 48 hours after connecting the peripheral nerve catheter. Secondary outcomes were pain scores, motor and sensory block, numbness, patient satisfaction and rescue analgesia. The return of sensory function after removal of the catheter was also assessed.

\section{Patients and Methods}

This single-institution, prospective, double-blind randomized trial design was approved by the Hospital Ethics Committee of the University Hospital Antwerp and was registered at clinical.trials.gov NCT02293330. The trial was conducted in accordance with the Declaration of Helsinki.

Foot surgery of the metatarsophalangeal (MTP) joint (Scarf-Akin, Keller, MTP arthrodesis, Weil osteotomy, Hoffmann resection) at the Antwerp University Hospital is performed under general anesthesia with a popliteal nerve catheter for postoperative analgesia. All patients, aged $\geq 18$ years, undergoing such surgery were asked to take part and give informed consent. Patients with neuromuscular diseases, peripheral neuropathy in the lower limb, chronic pain or any contraindication for a sciatic nerve block in their medical history were excluded.

The anesthesiologist performing the block, the patient and the independent observer were unaware of the study group. The data and observations were collected at the ward by a study nurse, who also collected the data out of the PCA pump after 48 hours.

Patients were randomized by a computer-generated sequence and concealed in sealed envelopes to either a continuous infusion of LA (group A) or to the PIB group (group B). The envelope was opened, and the pump prepared by an independent anesthesiologist who did not participate in registration of the parameters.

At arrival in the preparation room, an IV access was established, and standard monitoring was applied (blood pressure, ECG, and pulse oximetry).

An experienced anesthesiologist performed all the blocks in the lateral decubitus position with a 12-18 $\mathrm{MHz}$ linear probe (BK medical) and a Pajunk SonoLong needle/catheter set (18-gauge needle, 20-gauge catheter).

The nerve was visualized in a short axis image and the paraneurium was pierced at the exact junction of the peroneal and tibial nerve where they are adjacent but still can be distinguished in the ultrasound image to prevent intraneural injection with an out of plane technique as seen in Figure 1.

Confirmation of accurate needle tip position was confirmed by injection of $\mathrm{NaCl} 0.9 \%$ between the peroneal and tibial nerve in the paraneural sheath (Figure 2).

After confirmation of correct needle tip position, $15 \mathrm{~mL}$ levobupivacaine $0.25 \%$ was injected in between the peroneal and tibial nerve as a single location injection technique with intermittent aspiration every $5 \mathrm{~mL}$ to prevent intravascular injection. After injection, a catheter was advanced $4 \mathrm{~cm}$ beyond the needle tip.

The location of the catheter tip was checked with ultrasound in short and long axis with the guide wire still in place and with a bolus of $\mathrm{NaCl} 0.9 \%$ after removing the guide wire. When correct catheter placement could not be confirmed, the patient was excluded from the study. The depth of the catheter and time of local anesthetic injection was registered. The sensory block of the peroneal and tibial nerve was separately tested by loss of cold sensation at the dorsal and plantar side of tows before transfer to the

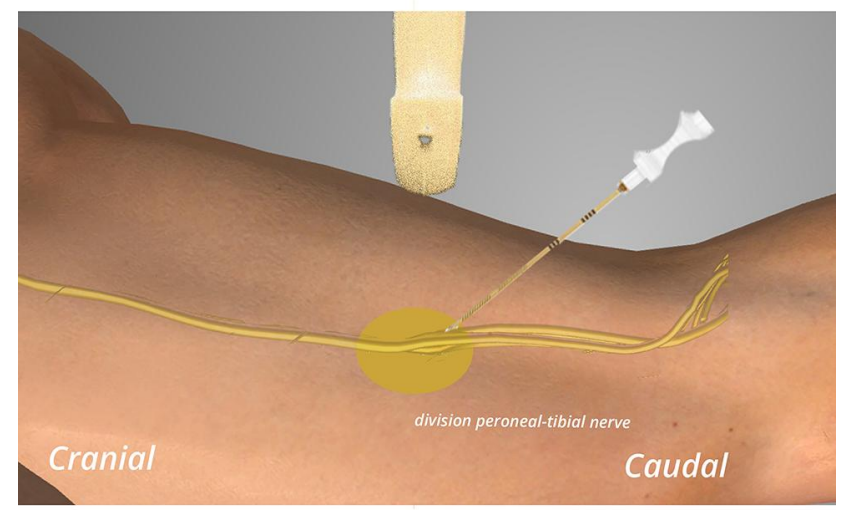

Figure I Out of plane puncture at the division of the tibial and peroneal nerve. 


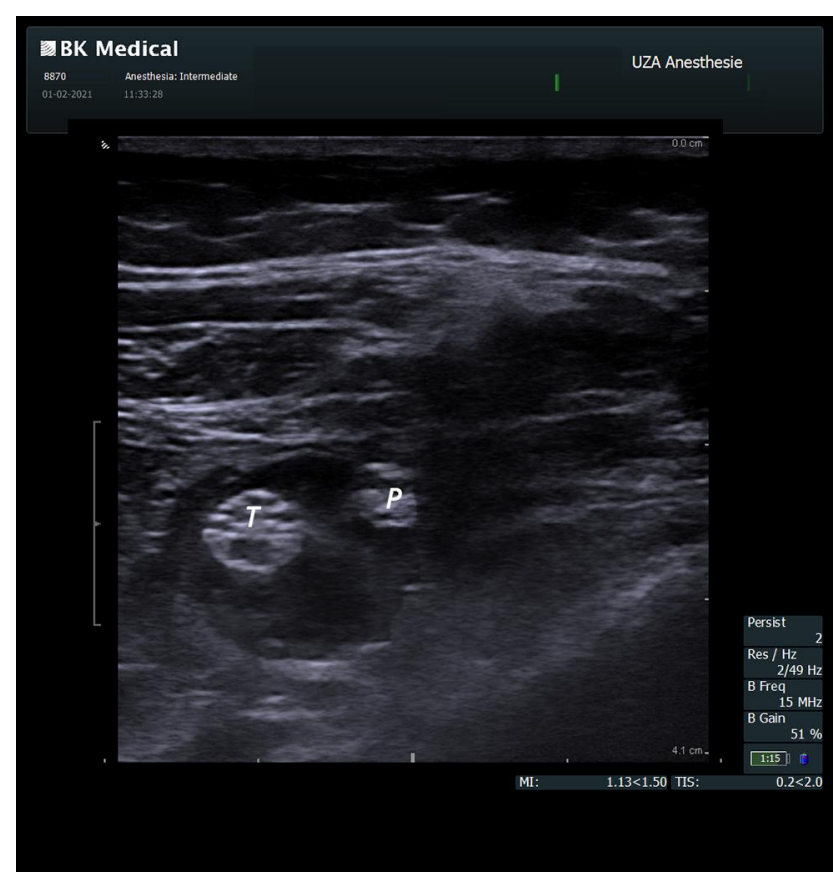

Figure 2 Injection of fluid in between the tibial $(T)$ and peroneal $(P)$ nerve.

operating room, at least 20 minutes after the initial injection of levobupivacaine $0.25 \%$. When no block was detected it was considered as a block failure and the patient was excluded from the study.

General anesthesia with a laryngeal mask was performed with propofol and sufentanil and maintained by sevoflurane and sufentanil increments. Surgery was performed with a tourniquet at $300 \mathrm{~mm} \mathrm{Hg}$ at the upper thigh. Duration of surgery was registered.

After surgery, patients were transferred to the recovery room. Here the infusion of the sciatic nerve catheter was initiated according to the study group by an independent anesthesiologist:

Group A: continuous infusion of levobupivacaine $0.125 \%$ at $5 \mathrm{~mL} / \mathrm{h}$. Optional patient-controlled bolus dose $6 \mathrm{~mL}$, lock out 30 minutes, 4 hours limit: $60 \mathrm{~mL} / \mathrm{h}$.

Group B: intermittent bolus of levobupivacaine 0.125\%: $0.1 \mathrm{~mL} / \mathrm{h}$ and $9.8 \mathrm{~mL}$ bolus every 2 hours. Optional patient-controlled bolus dose $6 \mathrm{~mL}$, lock out 30 minutes, 4 hours limit: $60 \mathrm{~mL} / \mathrm{h}$.

The first intermittent bolus was programmed 15 minutes after catheter connection.

The Pump (CADD Smiths medical) was started in the recovery room by an anesthesiologist who was aware of the appointed study group (group A or group B). Standard monitoring (ECG, pulse oximetry and non-invasive blood pressure) was applied and pain scores on an NRS
(Numeric Rating Scale) were registered every 30 minutes during recovery. Motor block (movement of toes yes or no), sensory block (loss of cold sensation at the dorsal (peroneal nerve) and plantar side (tibial nerve) of the tows) and the presence of numbness were registered (subjective feeling of numbness yes/no) for the first time when patients were sufficiently awake enough to evaluate these parameters.

Patients were transferred to the ward after clear instructions on how to use the pain pump. Pain scores were registered every 4 hours on the ward.

When pain control was insufficient (NRS $>3$ ) at the recovery room or on the ward, patients received paracetamol $1 \mathrm{gr}$ IV and ketorolac $30 \mathrm{mg}$ IV. Tramadol IV $2 \mathrm{mg} / \mathrm{kg}$ was given as rescue analgesia. All medication was registered. On the ward, the presence of a motor block (defined as possibility of toe movement yes or no), sensory block (tested by cold sensation at the dorsum and plantar side of the tows) and the sensation of numbness ( $0=$ no, $1=$ yes but non-disturbing $2=$ yes and disturbing) were registered at 6 , $12,24,30.36$ and 48 hours after starting the pump.

The pain pump was stopped after exactly 48 hours and all data were collected and filed. This file consisted of a detailed description of the history log of LA administered, like total LA dose in $\mathrm{mL}$ and $\mathrm{mg}$, frequency and time of extra boluses required.

After stopping the pump, the patient was asked if he or she was satisfied using a satisfaction scale score (1: very unsatisfied 10: very satisfied).

The patient was asked to register the exact time point where he or she experienced that the numb feeling disappeared, and normal sensation returned. The patient was called 2 days after discharge to register these parameters.

\section{Statistical Analysis}

We considered a $20 \%$ difference in LA dose between groups as a clinically relevant difference. We used a standard deviation of $25 \%(58 \mathrm{mg})$ based on data obtained from a previous study. ${ }^{8}$ The calculated minimum sample size required was 20 patients per group for a power of $80 \%$ with a 2-tailed significance level of $5 \%$.

Statistical analysis was performed with IBM SPSS statistics for mac version 23. Data distributions were tested with a Kolmogorov-Smirnov test. For normally distributed data, groups were compared with a Student's $T$-test. Non-normally distributed data were compared with a Mann-Whitney $U$-test. Categorical data distributions were compared with a X-square test. 


\section{Results}

From December 2014 to May 2016, 168 patients were screened, and 58 patients were randomized after giving informed consent. Four patients were not randomized because of poor visualization of the catheter. Fourteen patients were excluded after randomization due to protocol violation, catheter-related problems or lost data of the pump and 42 patients remained for analysis (Figure 3). Demographic data, the time interval between the block and the start of the pump and depth of the catheter were comparable and are presented in Table 1.

LA consumption is shown in Table 2. Total LA dose consumption was significantly higher for group A (293 $\pm 60 \mathrm{~mL})$ compared to Group B $(257 \pm 33 \mathrm{~mL})$. However, the amount of patient-controlled analgesia did not differ between groups. In 21 out of 23 patients, several programmed boluses were postponed because they fell in the lock out window of 30 minutes after a PCA bolus.

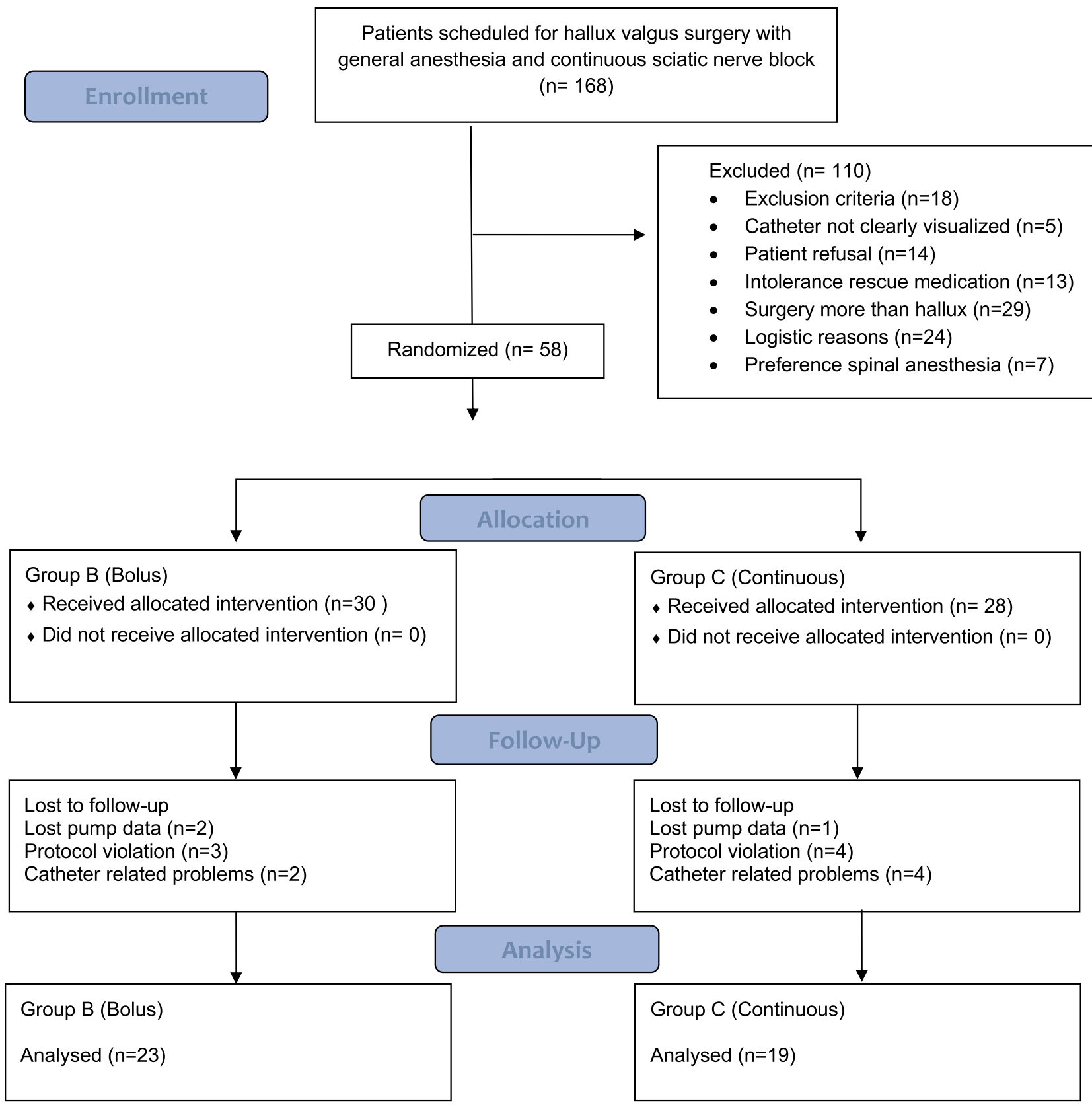

Figure 3 Flow diagram in conductance with the Consolidated Standards of Reporting trials (CONSORT). 
Table I Demographic Data, Catheter Depth and Starting Interval Pump

\begin{tabular}{|l|c|c|c|}
\hline & $\begin{array}{c}\text { Group } \\
\text { A (n= 19) }\end{array}$ & $\begin{array}{c}\text { Group } \\
\text { B (n=23) }\end{array}$ & P \\
\hline Weight (kg) & $63(11)$ & $71(14)$ & 0.3 \\
Length (cm) & $166(6)$ & $168(8)$ & 0.4 \\
Age (years) & $52(14)$ & $54(15)$ & 0.7 \\
Catheter depth (cm) & $9(0.6)$ & $9(0.7)$ & 0.9 \\
Time from injection-start & $110(28)$ & $104(24)$ & 0.4 \\
pump (min) & & & \\
\hline
\end{tabular}

Notes: Data are presented as mean (sd). Group $A=$ continuous group, group $B=$ intermittent bolus group.

Table 2 LA (Local Anesthetic) Dose Administered Over 48 Hours

\begin{tabular}{|l|c|c|c|}
\hline & $\begin{array}{c}\text { Group } \\
\text { A (n=19) }\end{array}$ & $\begin{array}{c}\text { Group } \\
\text { B (n=23) }\end{array}$ & P \\
\hline Total LA $(\mathrm{mL})$ & $293(60)$ & $257(33)$ & 0.02 \\
PCA LA $(\mathrm{mL})$ & $53(13)$ & $75(89)$ & 0.06 \\
Intermittent bolus LA $(\mathrm{mL})$ & 0 & $178(60)$ & \\
Continuous LA $(\mathrm{mL})$ & $240(0.3)$ & 4.8 & \\
\hline
\end{tabular}

Notes: Data are presented as mean (sd). Group A= continuous group, group $\mathrm{B}=$ intermittent bolus group.

Abbreviation: PCA, patient-controlled analgesia.

There was no difference in the distribution of PCA requests between groups.

Motor and sensory block characteristics at the time of catheter removal after 48 hours are displayed in Table 3.

A sensory block was present in both peroneal and tibial sensory area in 59\% (group A) and 50\% (Group B) of the cases.

Table 3 Block Characteristic at Catheter Removal After 48 Hours

\begin{tabular}{|l|c|c|c|}
\hline & $\begin{array}{c}\text { Group } \\
\text { A (n= 19) }\end{array}$ & $\begin{array}{c}\text { Group } \\
\text { B (n=23) }\end{array}$ & P \\
\cline { 2 - 4 } & Group A & Group B & P-value \\
\hline $\begin{array}{l}\text { \% motor block } \\
\text { \% sensory block tibial }\end{array}$ & $21 \%$ & $29 \%$ & ns \\
area & $11 \%$ & $18 \%$ & ns \\
\% sensory block & $17 \%$ & $27 \%$ & ns \\
$\begin{array}{l}\text { peroneal area } \\
\text { \% sensory block both }\end{array}$ & $59 \%$ & $50 \%$ & ns \\
\hline
\end{tabular}

Notes: Data are represented as percentages (\%). Group $A=$ continuous group, group $B=$ intermittent bolus group.

Abbreviation: ns, nonsignificant.
Table 4 NRS Scores, Total Dose Extra Analgesia and Patient Satisfaction Scores

\begin{tabular}{|l|c|c|c|}
\hline & $\begin{array}{c}\text { Group } \\
\text { A (n=19) }\end{array}$ & $\begin{array}{c}\text { Group } \\
\text { B (n=23) }\end{array}$ & P \\
\hline $\begin{array}{l}\text { Highest NRS score mean (min-max) } \\
\text { Patient satisfaction median (min-max) }\end{array}$ & $5(0-9)$ & $3(0-8)$ & $\mathrm{ns}$ \\
Total doses IV paracetamol (1000mg) & 30 & $10(2-10)$ & $\mathrm{ns}$ \\
and IV ketorolac (30mg) & 88 & $\mathrm{~ns}$ \\
Total doses of IV tradonal (2 mg/kg) & 8 & 8 & $\mathrm{~ns}$ \\
\hline
\end{tabular}

Notes: $(0=$ no pain, $10=$ worst pain), and patient satisfaction ( $I=$ very dissatisfied $10=$ very satisfied). Data are expressed as median (min-max). Group $A=$ continuous group, group $B=$ intermittent bolus group.

Abbreviation: ns, nonsignificant.

The majority of the patients were able to move their toes at 12, 24, 30, 36 and 48 hours after starting the pump. There were no statistical differences in motor block at any time point between groups. The number of patients that experienced numbness was $64 \%$ in both groups. Only one patient in Group A experienced this numbness as disturbing.

Patient satisfaction and NRS scores are displayed in Table 4. The median NRS scores over 48 hours and the highest NRS scores were equally distributed in both study groups. The median satisfaction was high (9.5-10) in both groups. No additional analgesia was adminstered in the recovery room. On the ward 16 patients in group Areceived extra paracetamol and ketorolac. In group B 13 patients received additional doses of paracetamol and ketorolac in this 48 -hour period. In both groups, 8 patients needed additional tradonal. Total doses of extra analgesia are displayed in Table 4.

Many patients had to be called again because normal sensation did not return after 2 days. Sensation returned after $70 \pm 17$ hours in group B and $75 \pm 22$ hours in Group A. There were no signs of neurologic deficit in any patient at follow-up.

\section{Discussion}

In this study, we hypothesized that a targeted bolus administration of LA within the confined subparaneural anatomical space would allow for a lower LA consumption compared to administration in a continuous infusion mode. The suggested mechanism for an LA dose reduction in PIB is a higher injection pressure and less systemic uptake by which more neural tissue is reached. ${ }^{9}$

Taboada et al published two similar randomized trials comparing intermittent bolus versus continuous infusion in 
sciatic nerve catheters. Although the catheters in these trials were placed by neurostimulation, they found similar results in LA and pain score reduction. ${ }^{8,10}$

Our trial confirms a comparable reduction of local anesthetic dose by using the PIB technique. However, ultrasound implies a more accurate placement of the catheter compared to neurostimulation. ${ }^{11}$ Therefore, we expected a more pronounced difference compared to stimulation and more extensive local anesthetic spread within this defined sheat as described by Perlas et al with a single shot technique within the paraneurium. ${ }^{12}$ The LA doses and pain scores in our trial were however comparable to those of Taboada. ${ }^{8,10}$ Neither could we find difference in the percentage of the tibial and peroneal nerve block, implying more extensive local anesthetic spread.

Sztain et al compared a continuous infusion in catheters placed underneath the paraneurium with catheters placed superficial of the paraneurium. She also failed to demonstrate any advantages in pain scores, analgesic consumption or feeling of numbness by placing the catheter underneath the paraneural sheath. ${ }^{13}$

We hypothesize that the lack of LA reduction for a catheter placed inside the paraneural sheath could be explained due to a different local anesthetic uptake when injecting inside the paraneurium compared to injecting to the surrounding structures which contain more fat tissue and could function as a local anesthetic depot. ${ }^{14}$

Previous trials postulate that LA dose instead of volume is the only determining factor for LA need in a continuous infusion. ${ }^{15,16}$ However, the doses used in these trials were considerably higher compared to our trial, and differences might be more pronounced with lower doses.

A recent meta-analysis investigating the benefit of the PIB technique for peripheral and truncal nerve analgesia was unable to draw any data-driven conclusions towards preferable anesthetic delivery method. ${ }^{9}$

The question rises if a reduction of $45 \mathrm{mg}$ levobupivacaine in 48 hours is clinically relevant. Since the dose given in 48 hours does not differ much with the maximum recommended dose for a single shot popliteal nerve block, the authors shared opinion is that concerning local anesthetic systemic toxicity (LAST) this reduction is not clinically relevant. Any differences in patient satisfaction, motor block or disturbing numbness as a result of the $45 \mathrm{mg}$ dose reduction could not be demonstrated in this trial. However, concerning the detection of compartment syndrome and the risk of neurotoxicity, there is a consensus that " less is better" especially since the catheter is placed in close proximity to the nerves within the paraneurium. ${ }^{17,18}$ However, the optimal dose/concentration has yet to be determined.

The mean return of normal sensation was 72 hours. Not much information is available in the literature concerning the duration of sensory block after removal of a sciatic nerve catheter. However, after a single shot, de duration of analgesia varies between 6 and 20 hours, depending on the dose, kind of local anesthetic, the additives used and the presence of diabetes. ${ }^{19-21}$ There are no trials investigating the duration of the sensory block after catheter removal. In our trial, the mean duration of sensory block after catheter removal seems substantially longer than generally assumed based on the theoretical duration of action of levobupivacaine.

The results of the present study should be interpreted within the constraints of the methodology used.

The safety of this technique could be debatable because of the risk of neural damage with the placement of the catheter within the paraneural sheath. ${ }^{22,23}$ All our patients resumed normal motor and sensory function within 7 days.

We did not give the initial bolus dose through the catheter, what could confirm correct catheter placement according to some authors. ${ }^{24}$ The failure rate of catheter placement by stimulation is as high as $10-40 \% .{ }^{25}$ Data produced by a stimulation technique are not automatically applicable to an ultrasound technique. ${ }^{26}$

A $20 \%$ increase in success rate was shown with ultrasound placement of popliteal catheters in a previous study and the probability of catheter dislodgement diminishes by placing it longitudinal to the nerve. ${ }^{27,28}$ However, we did not reconfirm correct catheter placement after surgery or on the ward. This means that we could have missed catheter dislodgement.

Several programmed boluses were postponed because they fell in the lock out window of 30 minutes after a PCA bolus.

We used levobupivacaine as loading dose which could mask a bigger difference between the two techniques the first 8-12 hours.

Furthermore, there might be more factors that influence the success of a postoperative continuous sciatic nerve catheter such as catheter orifice configuration or other yet unknown factors. ${ }^{29}$ We placed the catheter in an out-ofplane technique with a single end hole and used a dose regimen based on stimulation placed catheters. There are no solid data on dose regimens, catheters and optimal 
placement techniques, therefore changing one of these factors might change the outcome of this study.

\section{Conclusion}

In conclusion, programmed intermittent bolus administration with levobupivacaine $0.125 \%$ in a subparaneural sciatic catheter provided a dose reduction of $45 \mathrm{mg}$ compared with a continuous infusion technique. The subparaneural placement of the catheter did not cause any complications or neural deficit and return of normal sensation after catheter removal is longer than expected. More research is needed to identify the optimal dose, volume, and time interval for this regimen.

\section{Data Sharing Statement}

Data are available on request to the corresponding author.

\section{Funding}

No funding was received for this study.

\section{Disclosure}

The authors report no conflicts of interest in this work.

\section{References}

1. Singelyn FJ, Aye F, Gouverneur JM. Continuous popliteal sciatic nerve block: an original technique to provide postoperative analgesia after foot surgery. Anesth Analg. 1997;84(2):383-386. doi:10.1213/0000 0539-199702000-00027

2. Ilfeld BM, Morey TE, Wang RD, et al. Continuous popliteal sciatic nerve block for postoperative pain control at home: a randomized, double-blinded, placebo-controlled study. Anesthesiology. 2002;97 (4):959-965. doi:10.1097/00000542-200210000-00031

3. Zaric D, Boysen K, Christiansen J, et al. Continuous popliteal sciatic nerve block for outpatient foot surgery-a randomized, controlled trial. Acta Anaesthesiol Scand. 2004;48(3):337-341. doi:10.1111/j.00015172.2004.0327.x

4. White PF, Issioui T, Skrivanek GD, et al. The use of a continuous popliteal sciatic nerve block after surgery involving the foot and ankle: does it improve the quality of recovery? Anesth Analg. 2003;97:1303-1309. doi:10.1213/01.ANE.0000082242.84015.D4

5. Casati A, Vinciguerra F, Cappelleri G, et al. Levobupivacaine $0.2 \%$ or $0.125 \%$ for continuous sciatic nerve block: a prospective, randomized, double-blind comparison with $0.2 \%$ ropivacaine. Anesth Analg. 2004;99:919-23, table of contents. doi:10.1213/01.ANE.00001299 77.44115 .93

6. Ilfeld BM, Loland VJ, Gerancher JC, et al. The effects of varying local anesthetic concentration and volume on continuous popliteal sciatic nerve blocks: a dual-center, randomized, controlled study. Anesth Analg. 2008;107:701-707.

7. Carvalho B, George RB, Cobb B, et al. Implementation of programmed intermittent epidural bolus for the maintenance of labor analgesia. Anesth Analg. 2016;123(4):965-971. doi:10.1213/ANE.0000000000001407

8. Taboada M, Rodriguez J, Bermudez M, et al. Comparison of continuous infusion versus automated bolus for postoperative patient-controlled analgesia with popliteal sciatic nerve catheters. Anesthesiology. 2009;110(1):150-154. doi:10.1097/ALN.0b013e318191693a
9. Jagannathan R, Niesen AD, D'Souza RS, et al. Intermittent bolus versus continuous infusion techniques for local anesthetic delivery in peripheral and truncal nerve analgesia: the current state of evidence. Reg Anesth Pain Med. 2019;44:447-451. doi:10.1136/rapm-2018100082

10. Taboada M, Rodriguez J, Bermudez M, et al. A "new" automated bolus technique for continuous popliteal block: a prospective, randomized comparison with a continuous infusion technique. Anesth Analg. 2008;107(4):1433-1437. doi:10.1213/ane.0b013e3181824164

11. Schnabel A, Meyer-Friessem CH, Zahn PK, et al. Ultrasound compared with nerve stimulation guidance for peripheral nerve catheter placement: a meta-analysis of randomized controlled trials. $\mathrm{Br}$ J Anaesth. 2013;111(4):564-572. doi:10.1093/bja/aet196

12. Perlas A, Wong P, Abdallah F, et al. Ultrasound-guided popliteal block through a common paraneural sheath versus conventional injection: a prospective, randomized, double-blind study. Reg Anesth Pain Med. 2013;38(3):218-225. doi:10.1097/AAP.0b013e31828db12f

13. Sztain JF, Finneran JJ, Monahan AM, et al., Continuous popliteal-sciatic blocks for postoperative analgesia: traditional proximal catheter insertion superficial to the paraneural sheath versus a new distal insertion site deep to the paraneural sheath. Anesth Analg. 2018.

14. Song Y, Lee S, Paik DJ, et al. "Fat Brook" in the popliteal fossa: cadaveric and clinical investigation with magnetic resonance imaging. J Comput Assist Tomogr. 2017;41(3):494-498. doi:10.1097/ RCT.0000000000000549

15. Madison SJ, Monahan AM, Agarwal RR, et al. A randomized, triple-masked, active-controlled investigation of the relative effects of dose, concentration, and infusion rate for continuous popliteal-sciatic nerve blocks in volunteers. Br J Anaesth. 2015;114 (1):121-129. doi:10.1093/bja/aeu333

16. Bombardieri AM, Maalouf DB, Kahn RL, et al. A comparison of two different concentrations and infusion rates of ropivacaine in perineural infusion administered at the same total dose for analgesia after foot and ankle surgery: a randomized, double blinded, controlled study. Minerva Anestesiol. 2019;85(2):139-147. doi:10.23736/ S0375-9393.18.12266-8

17. Verlinde M, Hollmann MW, Stevens MF, et al. Local anesthetic-induced neurotoxicity. Int J Mol Sci. 2016;17(3):339. doi:10.3390/ijms 17030339

18. Yang S, Abrahams MS, Hurn PD, et al. Local anesthetic Schwann cell toxicity is time and concentration dependent. Reg Anesth Pain Med. 2011;36(5):444-451. doi:10.1097/AAP.0b013e318228c835

19. Schoenmakers KP, Fenten MG, Louwerens JW, et al. The effects of adding epinephrine to ropivacaine for popliteal nerve block on the duration of postoperative analgesia: a randomized controlled trial. BMC Anesthesiol. 2015;15(1):100. doi:10.1186/s12871-015-0083-z

20. Vermeylen K, De Puydt J, Engelen S, et al. A double-blind randomized controlled trial comparing dexamethasone and clonidine as adjuvants to a ropivacaine sciatic popliteal block for foot surgery. Local Reg Anesth. 2016;9:17-24. doi:10.2147/LRA.S96073

21. Baeriswyl M, Taffe P, Kirkham KR, et al. Comparison of peripheral nerve blockade characteristics between non-diabetic patients and patients suffering from diabetic neuropathy: a prospective cohort study. Anaesthesia. 2018;73(9):1110-1117. doi:10.1111/anae.14347

22. Wolf FA, Gray AT. Sonography of the paraneural sheath of the sciatic nerve in the popliteal fossa: more than a bifurcation. Reg Anesth Pain Med. 2014;39(3):260-261. doi:10.1097/AAP.0000000000000036

23. Neal JM, Barrington MJ, Brull R, et al. The Second ASRA practice advisory on neurologic complications associated with regional anesthesia and pain medicine: executive summary 2015. Reg Anesth Pain Med. 2015;40(5):401-430. doi:10.1097/AAP.0000000000000286

24. Borgeat A, Blumenthal S, Lambert $\mathrm{M}$, et al. The feasibility and complications of the continuous popliteal nerve block: a 1001-case survey. Anesth Analg. 2006;103(1):229-33, table of contents. doi:10. 1213/01.ane.0000221462.87951.8d 
25. Salinas FV. Location, location, location: continuous peripheral nerve blocks and stimulating catheters. Reg Anesth Pain Med. 2003;28 (2):79-82. doi:10.1053/rapm.2003.50033

26. Ilfeld BM. Continuous peripheral nerve blocks in the hospital and at home. Anesthesiol Clin. 2011;29(2):193-211. doi:10.1016/j.anclin.20 11.04 .003

27. Bendtsen TF, Nielsen TD, Rohde CV, et al. Ultrasound guidance improves a continuous popliteal sciatic nerve block when compared with nerve stimulation. Reg Anesth Pain Med. 2011;36:181-184. doi:10.1097/AAP.0b013e31820d421f
28. Hauritz RW, Pedersen EM, Linde FS, et al. Displacement of popliteal sciatic nerve catheters after major foot and ankle surgery: a randomized controlled double-blinded magnetic resonance imaging study. Br J Anaesth. 2016;117:220-227. doi:10.1093/bja/aew172

29. Fredrickson MJ, Ball CM, Dalgleish AJ. Catheter orifice configuration influences the effectiveness of continuous peripheral nerve blockade. Reg Anesth Pain Med. 2011;36:470-475.

\section{Publish your work in this journal}

Local and Regional Anesthesia is an international, peer-reviewed, open access journal publishing on the development, pharmacology, delivery and targeting and clinical use of local and regional anesthetics and analgesics. The journal welcomes submitted papers covering original research, basic science, clinical studies, reviews \& evaluations, guidelines, expert opinion and commentary, case reports and extended reports. The manuscript management system is completely online and includes a very quick and fair peer-review system, which is all easy to use. Visit http://www.dovepress.com/testimonials. php to read real quotes from published authors. 